\title{
Литература
}

1.Мельников В.М., Юров И.А. Теоретические подходы к построению психологической модели «идеального» спортсмена // Спортивный психолог. 2013. - №3. - С.18-21.

2.Мельников В.М., Юров И.А. Акмеологические условия и предпосылки пргнозирования спортивных достижений//Спортивный психолог. -2014.-№1 (32).- C.34-38.

3. Мельников В.М., Юров И.А. Проблема индивидуальности в спортивной психологии // Спортивный психолог. 2014. - №3. - С.20-23.

4. Мельников В.М., Юров И.А. Структура личности в отечественной психологии / Известия Сочинского государственного университета.- 2014. № 42 (33). - С.158-162.

5. Мельников В.М., Юров И.А. Психологическое моделирование спортивной успешности/Спортивный психолог. - 2016. - №1(4)-С.34-36

6.Мельников В.М., Юров И.А.Психоакмеологические предикторы спортивный достижений / Ресурсы конкурентоспособности спортсменов: теория и практика реализации. Краснодар: КГУФКС и Т., 2016. -Т.1. №1. C.142-145.

7. Мельников В.М., Юров И.А. Экспериментальное исследование тревоги у спортсменов в зависимости от мотивации (закон Йеркса-Додсона в спорте) /Спортивный психолог. - 2016.-№2(41) - С. 70-74.

8. Юров И.А. Дифференциально-психологические свойства спортсменов. Германия (ЛАП), 2016.- 226 с.

9. Юрова К.И., Юров И.А. Психология личности: структура и функции//Дружининские чтения. Сб. материалов XIII Всероссийской научнопрактической конференции. г. Сочи. - Киров: МЦНИП, 2014. - С. 190- 192.

10. Юрова К.И., Юров И.А. Фрустрация как фактор неадаптивного поведения/Гуманизация образования.- №6.-2016.- С.110-115.

\section{ПРОБЛЕМЫ УПРАВЛЕНИЯ ПЕРСОНАЛОМ В ДЕЯТЕЛЬНОСТИ, ТРЕБУЮЩЕЙ РИСКА}

Попова В.С., Шаповалов В.И.

Статья направлена на изучение проблемы психологической готовности человека к безопасному поведению при выполнении деятельности в условиях риска. Актуальность работы связана с тем, что на территории Российской Федерации предприятия и организации, осуществляющие деятельность, связанную со строительством, реконструкцией объектов и их эксплуатацией, а также выполняющие сложные технологические процессы производства и труда, относятся к регламентируемым видам деятельности, связанные с жизнью и здоровьем человека, а также безопасностью объектов и окружающей среды.

Для этой категории работников разработаны четкие государственные нормативные требования, правила и правовые акты для функционирования в условиях производства работ с повышенной опасностью (риска). В основе документа лежат требования обеспечения безопасности работников в 
ситуациях воздействия опасных и вредных производственных факторов и создание для работников условий труда, предотвращающих опасность для их здоровья и жизни.

Формальная часть требований к выполнению работ в условиях повышенной опасностью (риска) определятся документом «наряд-допуск» соответствующего образца. Однако формальный допуск, ни в какой мере не определяет наличную психологическую готовность человека к успешному выполнению работ в условиях риска, а соответственно и качество самой работы. А именно психологическая готовность является важной и часто определяющей детерминантой успешности выполнения рабочего задания. В статье ставятся задачи:

- осветить значимость психологической готовности в деятельностях, связанных с риском;

- найти пути оценки психологической готовности с целью последующего надежного профессионального отбора кадров на работы, связанные с возможным риском.

Понятие «психологическая готовность» в деятельности, связанных с риском. Кузьмина Н.В. считает, что психологическая готовность к профессиональной деятельности характеризуется наличием у специалиста знаний, умений и навыков, позволяющих ему осуществлять свою деятельность на уровне современных требований науки и техники.[1].

Для деятельности связанной с риском такого определения психологической готовности явно недостаточно. Ибо риск (реальный или предполагаемый) как переменная профессиональной деятельности вносит существенную дополнительную, трудно учитываемую неопределенность в функционирование работника $\mathrm{C}$ точки зрения психологии в данном случае уместно работника в формальном виде рассматривать как множественно детерминированную систему, безопасное поведение которой обусловливается и достигается не только внешними обстоятельствами (задачами, целями, мотивацией и т.д.), но и внутренним содержанием, т.н «верхними этажами» структуры личности [2], (знаниями-умениями-навыками, способностями, опытом, компетентностью, интеллектуальным потенциалом и часто интуицией) и состоянием (самооценкой, самоактуализацией, ценностными ориентациями, тревогой, отношением к риску и т.д.) субъекта деятельности, то есть всем тем, что относится к содержанию концептуальной образ-модели [3].

Профессиональная деятельность является внешним проявлением функционирования психики. Изучая поведение, мы изучаем проявление личности во всем ее многообразии, многоаспектности и многомерности [4]. Безопасное поведение может реализовать только личностью безопасного muna поведения; такое поведение обуславливается сформированной концептуальной образ-моделью личности безопасного типа поведения. По нашему мнению психологическая готовность к деятельности, связанных с риском является важной составляющей этой модели. Речь идет о субъективных (скрытых от внешнего взгляда) компонентах детерминирующих психологическую готовность к деятельности в условиях возможно риска. 
Шадриков В.Д. в русле системогенетического подхода психологическую готовность личности к профессиональной деятельности рассматривает как определенное психическое состояние, характеризующееся определенными мотивационными и субъективным, операциональными свойствами, связанные с потенциями субъекта [5].

Данные свойства могут быть сформированы в ходе активной профессиональной подготовки с учетом индивидуальных особенностей индивида. Высокий уровень психологической готовности личности выступает необходимым условием достижения успеха в профессиональной деятельности. Несомненно, говоря о профессиональной подготовке специалистов, необходимо, прежде всего, учитывать уровень их личностного развития, ценностные ориентации и профессиональные установки. Учет данных факторов позволяет сделать максимально эффективным процесс профессиональной подготовки.

В статье рассматривается деятельность специалистов, работающих в сфере электроэнергетики. Специальность энергетика относится к одной из самых опасных профессий, среди других процессов производства и труда. Людям, работающим в данной деятельности, очень часто приходиться сталкиваться с риском воздействия вредного и опасного электрического тока, электрической дуги, что может привести к различным травмам, а также иметь фатальные последствия. Выбирают эту профессию, преимущественно люди с техническим складом ума, которые способны производить сложные математические подсчеты и могут анализировать различные схемы, графики и диаграммы. Работа в сфере электроэнергетики и электротехники требует от сотрудника хорошего внимания и умения концентрироваться, обладать высокой степенью личной ответственности, очень часто такие люди выступают как новаторы, применяя и внедряя самостоятельно новые подходы к привычной работе. Подбор персонала на данные вакансии ведется, как правило, по основным требованиям, таким как: профессиональные способности, уровень образования, квалификация. По нашему мнению, оценка кандидатов в их психологической готовности к работе связанной с риском, является не менее важным показателем пригодности к данной деятельности.

Таким образом, часто может присутствовать противоречие между формальным наличием профессиональных знаний у работника и, следовательно, его пригодности к выполнению работ, требующей риска и реальной личностной готовностью работника к надежному выполнению требуемых работ. А значит, управление персоналом электротехнического профиля должно учитывать особенности человека не только со стороны его профессиональных знаний и умений, которые безусловно являются важным фактором отбора на должность, но и психологические аспекты обеспечения безопасности профессиональной деятельности - психологическую готовность. С позиции системного подхода приведенное противоречие снимается, если рассматривать профессиональные знания и умения работника и его психологическую готовность как две системно связанных составляющих профессиональной деятельность, образующих в своем единстве 
профессиональную компетентность работника. Но, если, в процессе профотбора для оценки профессиональных знаний и умений разработано много методик, то оценка психологической готовности к деятельности, связанной с риском, как правило, не производится. А именно реализация имеющихся профессиональных знаний на фоне психологической готовности к еe выполнению превращает их в профессиональную компетентность.

Далее в статье описывается психологическая методика оценки личностной готовности к деятельности сопряженной с риском, основанная на модельном представлении готовности к выживанию в экстремальной ситуации.

Методика разработана в США в конце 1970-х годов майором войск специального назначения США Н. Роуи и психологом Э. Пилл. Авторы считают, что их методика это не панацея, а лишь один из инструментов для выявления тенденции к готовности кандидата на должность, сопряженной с риском [6].

По мнению авторов их методика направлена на определении образа мышления. Даже с учетом знаний, что стиль поведения, манеры и набор эмоциональных качеств у всех людей разный, создатели методики группируют всех людей в две категории.

Первая - продуктивная, способствующая успеху. Она позволяет адаптироваться к окружающей среде и даже взять ее под контроль. Именно, подобный образ мышления, позволяет человеку справляться с любыми опасными ситуациями. Вторая - пораженческая ведет к капитуляции перед собой.

В заключении приведем психологическую характеристику человека продуктивного стиля поведения, способствующего выживанию:

- ясное понимание цели и способность просчитывать свои действия для ее достижения;

- осознание стимула, воли, настойчивости продолжать движение, даже когда вокруг все не в вашу пользу;

- оптимизм - позитивный взгляд на жизнь и чувство юмора - способен поддержать ваш настрой и вести вас вперед, несмотря на тягостные моменты;

- контроль за своими действиями и вера, что ваши действия принесут результат. Это помогает избежать чувство беспомощности, которое вынуждает многих ломаться;

- рачиональное мышление - логический подход к решению проблем;

- нетрадиционное мышление позволяет вам импровизировать, использовать имеющиеся под рукой средства и ресурсы и находить решения для нестандартных ситуаций, не описанных в учебниках и наставлениях;

- адаптивное мышление позволяет приспособиться к ситуации, быть более гибким, меняться, когда это необходимо и сохранять спокойствие в случае неопределенности;

- положительная самооценка как основа, на которой выстраивается остальная стратегия.

Таким образом, психологическая характеристика работника на фоне его предметных знаний и умений поможет ему сформировать адекватную «Я- 
концепцию» оберегающую его от возможных неверных действий в ситуациях неопределенности, возможности риска.

Подводя итоги, мы констатируем, что проблема готовности человека к безопасному поведению в своей деятельности, а также возможность его личностных характеристик к действиям, направленным на предотвращение опасных и чрезвычайных происшествий, а также корректному поведению в ситуациях в условиях риска, являться важным качеством специалиста энергетики. Одной из задач в управлении персонала этой отрасли стоит раскрытие индивидуальные свойств личности, а также поддержка и развитие потенциала сотрудников в готовности к деятельности в условиях риска.

\section{Литература}

1. Проблемы профессиональной подготовки специалистов в вузах // Проблемы отбора и профессиональной подготовки специалистов в вузах" Под ред. Н.В. Кузьминой. - Л., 1970

2. Новиков, А.М. Методология [Текст] / А.М. Новиков, Д.А. Новиков. М. : СИНТЕГ, 2007. -668 с

3. Дружилов С.А. Обобщенный (интегральный) подход к обеспечению становления профессионализма человека. Психологические исследования, 2012a, No. 1(21), 2. http://psystudy.ru

4. Пиаже Ж. Избранные психологические труды / [пер. с фр.]. - М. : Просвещение, 1969. - 659 с.

5. Ананьев, Б.Г. О проблемах современного человекознания [Текст] / Б.Г. Ананьев. - СПб. : Питер, 2001. - 380 с

6. Тест на способность к выживанию, Режим доступа: https://extremesurvival.io.ua/s191364/test_na_sposobnost_k_vyjivaniyu]

\section{ОСОБЕННОСТИ МОТИВАЦИИ ЖЕНЩИНЫ-РУКОВОДИТЕЛЯ. Хондаченко Н.В., Петросьян С.Н.}

Аннотация: В данной статье рассматривается актуальность проблемы в сфере мотивации женщины-руководителя. Данная проблема обусловлена тем, что в настоящее время женщины все больше занимают руководящие посты, в то время когда довольно длительный промежуток такое положение было прерогативой мужчин. За последние годы выросло число женщинпредпринимателей в малом бизнесе. На сегодня существуют работы по изучению гендерных различий, сильных и слабых сторон руководства . При этом существует недостаточная изученность особенностей мотивации руководителя-женщины.

Мотивация - наличие причинно-следственной связи между чем-либо (поступками, действиями, явлениями) [1]. Мотивация есть процесс побуждения человека к деятельности во имя достижения определенных целей) [2]. Мотив (от фp. motif) - внутренняя причина, побуждающая к какому-либо действию или деятельности. Совокупность мотивов характеризует личность человека в социальной системе и обусловливает его поведение и реакцию на внешние 